\title{
Drug in The Workplace
}

\author{
Khatijah Taharah Binti Mohamed Shah \\ Universiti Sains Malaysia 11800 Penang \\ taharah93@gmail.com
}

\begin{abstract}
The abuse of illicit drug leads to many short-term and long-term negative physical effects such as hallucinations, loss of coordination, and in severe cases even death. To add on, drug abuse may also lead to serious harm to the organization and its employee. For example, the effects of consuming drugs in the workplace are reduced workforce size, increase in absenteeism and loss of productivity. The government has made an effort to curb it by having a six-point program which targets the management, workplace policy, educating the employees, drug screening, availability of treatment and corporate sponsorship.
\end{abstract}

Keywords: drug use, workplace, danger, effects.

\section{INTRODUCTION}

Drug is any substance that provides nutritional support to the body besides food that can also have physiological changes when inhaled, injected, smoked, consumed or absorbed via patch (Drugs.com). There is however a difference between using drugs and abusing them. Abusing drugs would be using any illicit drugs that may affect the health of the user or any other individual (Collins, \& Lapsley, 2008). Thus, drug abuse, rather than drug use would the matter at hand that will be discussed, since drug use, can be for a number of reasons, mainly for medicinal purposes. Social costs of drug abuse can bear upon one or more of four community groups which are the ill-informed group, other individuals, business, government (Collins \& Lapsley, 2008). Business places are suffering the brunt of drug use both in the company and in their surrounding environments. Thus, it is an important factor in discussing on drug use and abuse.

\section{Statistics of Drug Use in Workplace}

A combined data obtained from the year 2008-2012 shows that annually an average of $8.7 \%$ of workers drank copious amounts of alcohol while on the job, while $8.6 \%$ were using illicit drugs and $9.5 \%$ were dependent on alcohol and drugs to carry on normal dayto-day activities (Bush, \& Lipari, 2013).

In Malaysia drug misuse during work has been a concern for a number of years. As reported by the Borneo post, a government staff from Kota Samarahan was caught using drugs namely amphetamine and methamphetamine and was apprehended by the Narcotics Crime Division of Limbang District Police and the case is being investigated (Borneo Post, 2017).

\section{Types of Drugs}

Under section 24 (1) of the Occupational Safety and Health Act 1994 from the Department of Occupational Safety and Health, states that "employee has the obligation to take reasonable care of his own safety and health and other persons who may be affected by his actions at work". This is the reason employees are not supposed to be taking, inhaling or injecting drugs in to their system since it could be detrimental to their health and the health of others.

There are six types of drugs that is classifies under the Occupational Safety and Health Act 1994, that could be called illicit drugs. These are opiates that include opium, heroin, morphine, codeine, etc., cannabis including ganja and marijuana, depressants, stimulates (such as cocaine and amphetamine), hallucinogens (LSD) and other designer drugs such as Ecstasy (MDMA) etc. (Department of Occupational Safety and Health, 1994) These are the drugs that would have the most negative effects on a person and the people around them.

Opiates are drugs that work on the receptors to produce copious amounts of dopamine (hormones responsible for feeling happy) which is where the 'high' feeling comes from and why opiates such as heroin as common abused illicit drugs (Lindesmith, 2008). However, opiates such as Heroin have adverse effects that could cause mortality.

Cannabis such as ganja and marijuana are psychoactive drug that has hallucinogenic properties on the user. Though it can be pleasurable to inhale or intake, it has several diverse outcomes such as having a low sperm count, have lesser attenuated dopamine (DA) as compared to normal and non-drug users and at higher risk for depression (Lev-Ran, Roerecke, Le Foll, George, McKenzie, \& Rehm, 2014; Volkow, et. al, 2014).

Next are depressants such as benzodiapines, which were not made to harm rather the original intention was for treatments of anxiety, tension and insomnia. Classes of benzodiapines include benzodiapem, alprazolam, clonazapem, lorazepam and barbiturates (Glass, 2016). Misuse of benzodiapines, can cause respiratory problems such as pneumonia and chronic obstructive pulmonary disease (COPD). It can also increase the risk of being hospitalized due to these two illnesses (Vozoris, 2014). 
The next classification is stimulants such as cocaine and amphetamine. Cocaine and amphetamine are pharmacologically different but they both affect the central nervous system in similar manners. Cocaine can also have medicinal benefits as it is a natural aesthetics but when misused decreases the amount of Omega- 3 in the body that might synergistically influence the stress susceptibility (Serrano, Rodriguez, Geste, Pompilus, Wickensonn \& Maldonado-Vlaar, 2016).

\section{Prevention of Drug Use}

\section{Symptoms of drug use}

For employers or other work colleagues, it would be good to know the signs and symptoms when their employee or colleague is using the drugs. The common symptoms would be panic attack, blurred vision, unsteady gait, fear, excessive sweating, irritability, weakness, and increased heart rate. In more severe cases that could lead to obvious symptoms such as paranoia and delusions (Gurney, Scott, Kacinko, Presley, \& Logan, 2014). If an employee is exhibiting these symptoms or signs, it could be because of illicit drug use, but it could also be due to other illness, thus, it is good to keep a look out for these signs and symptoms but it is also important to keep in mind to check first before any allegations or accusations are made.

\section{Profession with highest risk}

The profession with frequent users of drug users were found to be commercial truck drivers. This is because they work long hours and often take double shifts and in order to stay awake the would ingest drugs such as amphetamine and cocaine which are drug stimulants to stay awake and alert while driving on the job. However, these drugs could have harmful side effect such as dizziness, vertigo, hallucinations and change of perception and reactions (Girotto, Mesas, de Andrade, \& Birolim, 2013).

In order to decrease the usage of drug among truck drivers, companies ought to give better working conditions, such as better benefits such as food plans and health plans. This would hopefully decrease the usage of drug use due to income below levels determined by minimum wage labour agreements and use some productivity-based earnings Thus, a comprehensive and participatory approach and action needs to be taken to reduce absenteeism, tardiness, work accidents, general deterioration health of workers and other increased safety risks due to the usage of drugs (Caverley, Cunningham, \& MacGregor, 2007).

\section{Effect of using drug in the workplace}

Drug abuse can have an important impact upon the productivity of the paid workforce in three ways which are reduced workforce size, absenteeism and loss of productivity.

\section{Reduced workforce size}

A company needs a certain number of workers to function, whether it is on their production line or their management sector. If drug usage in the company is rampant, the net production for that year would decrease and that would be due to the low manpower or high turnover rate caused by the effects of drug use (Collins \& Lapsley, 2008). As discussed above, drug use has many symptoms ranging from causing lethargy to causing hyperactiveness; if an employee were to have either of these symptoms, it would delay production since they are not able to concentrate and give their fullest attention on the job at hand.

In addition to that, if the addict were to die due to overdose, which is common from heroin addicts, the time taken to replace the worker would also cause a delay in the production line. Thus, when an estimate is made, from national accounts data, of the difference in potential production levels between the actual workforce and the counterfactual, no drug abuse, workforce, the no drug abuse, production line had higher revenue and profit (Collins \& Lapsley, 2008).

\begin{abstract}
Absenteeism
Drug users, were twice as likely to be absent as compared to non-drug users. Especially, for male workers as compared to female drug users. An estimate of 7,400,000 workdays were lost because of drug use. It was also speculated that because most cases of illicit drug abuse go unreported the actual number could be much more. (Duraisingam, Pidd, \& Roche, 2009). This shows that a large amount of companies are undergoing possible low work productivity due to illicit drug use, without even knowing it.
\end{abstract}

\section{Loss of productivity}

On-the-job productivity would decrease substantially if an employee were using drugs, due to the effects that drugs produce. Some causes lethargy, while others loss of concentration and hyperactivity (Collins, \& Lapsley, 2008).

The total cost for drug use in the workplace to the employer is whopping 1662.9 Million Australian dollars per year due to the lack of production. For health, the cost is another 201.7 Million Australian dollars that either the workplace that has health care benefits, the health insurance company and the government funding that is being supplied for drug use per year (Collins, \& Lapsley, 2008).

Loss of production could also be due to high levels of turnover in the company by workers who either overdosed on drugs, or has been forced to stop working due to being a drug user that causes many days of absenteeism and sick leave. That does not include the employee who voluntarily left the job, due to being unable or lazy to work. However, if unemployment in the society were to become rampant, usage of drugs would also decrease (Collins, \& Lapsley, 2008). This could be due to the addicts being unable to support their drug habits, thus will no longer be using.

\section{Six Point Programme}

Tan Sri Lee Lam Thye, the vice-chairman of Malaysia Crime Prevention Foundation said that there was a need for an implementation of drug-free 
workplace policy to benefit employers and employee which are providing job security to employees, and productivity and profitability for employers.

He further highlighted that a drug free workplace could be achieved through a six-point programme (News Straits Times, 2016):

1. MANAGEMENT which is the commitment of both the employers and employees as well as leadership strength of upper management to work towards a drug-free workplace.

2. Having a DRUG-FREE workplace policy and committee to help with activities that could lead to a drug-free workplace by utilising programmes, etc.

3. EDUCATING employee and having an employee awareness programme on the dangers of drug abuse as mentioned and the reasons why workforce should be free of drugs.

4. DRUG screening to detect drug abuse at workplaces;

5. TREATMENT referral to enable employers to assist employees. Drug users should be given help, counselling, treatment, and rehabilitation, instead of dismissing them and making them a threat to the community.

6. CORPORATE sector involvement to provide sponsorship to help credible non-governmental organisations in carrying out sustained anti-drug campaigns at the community level.

\section{Corporate and NGO Sectors}

The last step in the six point programme is having corporate sectors work hand-in-hand with nonprofitable organizations to eliminate drug use on a social level in that community. With this effort, corporate sectors would benefit as well, since the work environment would be a drug free environment that promotes lower employee turnover which results in a higher productivity rate. An example would be using the National Anti-Drug Campaign as a platform that promotes and facilitates this collaboration between these two organizations in a dedicated efforts to eradicate drugs not only the workplace but also the community.

\section{Challenges}

In any effort to effect change, there would be a set of challenges that accompanies it. One of the challenges is the cost incurred to put the six-point programme in place.

In addition to that, taking the time and effort to implement the policy could also be seen as a waste of resources, when there are plenty of other current responsibilities and job tasks that still need attending to. Coupled with the time needed to take off for the training period, makes most employees reluctant to join (Unwin, \& Wellington, 2013).

Lastly, the challenge would be due to the fact that Malaysians are collectivistic culture that emphasizes more on harmony, oriented towards a larger group and have respect and obedience (Tamis-LeMonda et al., 2007). Thus, they are less likely to callout a collegue that might have a drug problem, to maintain friendship and to sustain the harmionous atmosphere of the work environment.

\section{CONCLUSION}

As a conclusion, drug usage in the workplace of many types such as opium, depressants, cannabis, etc has many adverse side effects which include loss of concentration, hyperactivity, lethargic, etc. Thus, as a responsible employer, a creating a favourable work environment through many methods as mentioned is an important aspect to ascertain full work productivity as well as ensuring the happiness of the employees.

\section{REFERENCES}

Borneo Post,. (2017). Civil servant abusing drugs nabbed. Retrieved from http://www.theborneopost.com/2017/03/24/civilservant-abusing-drugs-nabbed/

Bush, D. M., \& Lipari, R. N. (2013). Substance use and substance use disorder by industry.

Caverley, N., Cunningham, J. B., \& MacGregor, J. N. (2007). Sickness presenteeism, sickness absenteeism, and health following restructuring in a public service organization. Journal of Management Studies, 44(2), 304-319.

Collins, D. J., \& Lapsley, H. M. (2008). The costs of tobacco, alcohol and illicit drug abuse to Australian society in 2004/05. Canberra: Department of Health and Ageing.

Department of Occupational Safety and Health, (1994). OCCUPATIONAL SAFETY AND HEALTH ACT 1994 (pp. 1-31).

Drugs.com | Prescription Drug Information, Interactions \& Side Effects. (2017). Drugs.com. Retrieved 13 April 2017, from https://www.drugs.com/

Duraisingam, V., Pidd, K., \& Roche, A. M. (2009). The impact of work stress and job satisfaction on turnover intentions: A study of Australian specialist alcohol and other drug workers. Drugs: education, prevention and policy, 16(3), 217-231.

Glass, I. B. (Ed.). (2016). The international handbook of addiction behaviour. Routledge.

Gurney, S. M., Scott, K. S., Kacinko, S. L., Presley, B. C., \& Logan, B. K. (2014). Pharmacology, toxicology, and adverse effects of synthetic cannabinoid drugs. Forensic Sci Rev, 26(1), 53-78.

Lev-Ran, S., Roerecke, M., Le Foll, B., George, T. P., McKenzie, K., \& Rehm, J. (2014). The association between cannabis use and depression: a systematic 
review and meta-analysis of longitudinal studies. Psychological medicine, 44(04), 797-810.

Lindesmith, A. R. (2008). Addiction and opiates. Transaction Publishers.

News Strait Times,. (2016). More than 130,000 drug addicts in Malaysia to date, figures show. Retrieved from http://www.nst.com.my/news/2016/04/140154/more -130000-drug-addicts-malaysia-date-figures-show

Serrano, S., Rodriguez, N., Geste, J. R., Pompilus, M., Wickensonn, N., \& Maldonado-Vlaar, C. (2016). Omega-3 deprivation enhance anxiety-like behaviors after abstinence from chronic cocaine consumption: possible synergistical effect of cocaine and nutrition. The FASEB Journal, 30(1 Supplement), 671-18.

Tamis-LeMonda, C., Way, N., Hughes, D., Yoshikawa, H., Kalman, R., \& Niwa, E. (2007). Parents' Goals for Children: The Dynamic Coexistence of Individualism and Collectivism in Cultures and Individuals. Social Development, 17(1), 183-209. http://dx.doi.org/10.1111/j.1467-9507.2007.00419.x
Unwin, L., \& Wellington, J. (2013). Young People's Perspectives on Education, Training and Employment: Realising Their Potential. Routledge.

Volkow, N. D., Wang, G. J., Telang, F., Fowler, J. S., Alexoff, D., Logan, J., ... \& Tomasi, D. (2014). Decreased dopamine brain reactivity in marijuana abusers is associated with negative emotionality and addiction severity. Proceedings of the National Academy of Sciences, 111(30), E3149-E3156.

Vozoris, N. (2014). Do benzodiazepines contribute to respiratory problems?. Expert Review Of Respiratory $\begin{array}{lcc}\text { Medicine, } & 8(6), & 661-663 .\end{array}$ 